\title{
HUBUNGAN PENGETAHUAN DAN SIKAP PUS DENGAN KONTRASEPSI IMPLANT DI PUSKESMAS SAMALAGA KABUPATEN BIREUEN TAHUN 2020
}

\section{The Relationship Of Knowledge And Pus Attitude With Implant Contraception In Samalanga Puskesmas Bireuen Disctrict 2020}

\author{
Sarika ${ }^{1}$ Bismi Ulia ${ }^{2}$ \\ ${ }^{1}$ Dosen Akademi Kebidanan Munawarah, ${ }^{2}$ Mahasiswi Akademi Kebidanan Munawarah \\ Jl. Sultan Iskandar Muda, No. 18 Kota Juang, Bireuen \\ rikatulhajanah@gmail.com
}

\begin{abstract}
ABSTRAK
Salah satu Metode Kontrasepsi Jangka Panjang (MKJP) adalah implant. Kontrasepsi Implant adalah metode kontrasepsi yang diinsersikan pada bagian subdermal, yang hanya mengandung progestin dengan masa kerja panjang, dosis, rendah, dan reversibel untuk wanita. Penelitian ini bertujuan untuk mengetahui hubungan pengetahuan dan sikap PUS dengan kontrasepsi Implant Di kecamatan Samalanga, Kabupaten Bireuen.

Penelitian ini merupakan jenis penelitian analitik dengan pendekatan cross sectional. Pengambilan sampel dalam penelitian ini dengan menggunakan teknik Accidental sampling berjumlah 43 orang Di Puskesmas Samalanga, Kabupaten Bireuen. Penelitian ini dilakukan pada tanggal 13-17 September 2020. Pengumpulan data melalui kuesioner. Teknik analisis data univariat menggunakan distribusi frekuensi dan analisis bivariat menggunakan uji chisquare.

Hasil uji statistik chi-square antara pengetahuan PUS tentang Kontrasepsi Implant diperoleh hasil nilai $\mathrm{p}$ value $(0,036)<$ dari $\alpha(0,05)$ maka hipotesis diterima $\left(\mathrm{H}_{0}\right.$ ditolak dan $\mathrm{H}_{\mathrm{a}}$ diterima), Dapat disimpulkan bahwa ada hubungan yang bermakna antara pengetahuan PUS dengan kontrasepsi implant. Dan hasil uji statistik chi-square sikap PUS dengan kontrasepsi implant diperoleh hasil nilai $\mathrm{p}$ value $(0,043)<$ dari $\alpha(0,05)$, maka hipotesis diterima $\left(\mathrm{H}_{0}\right.$ ditolak dan $\mathrm{H}_{\mathrm{a}}$ diterima). Dapat disimpulkan bahwa ada hubungan yang bermakna antara sikap PUS dengan kontrasepsi implant.

Diharapkan kepada responden untuk lebih aktif mencari informasi dan mengikuti berbagai penyuluhan khususnya tentang Kontrasepsi Implant. Hal ini dapat diperoleh dengan memperbanyak membaca dan mengikuti acara seminar.
\end{abstract}

Kata Kunci : Pengetahuan, Sikap, Kontrasepsi Implant 
Journal of Healthcare Technology and Medicine Vol. 6 No. 2 Oktober 2020

Universitas Ubudiyah Indonesia

e-ISSN : 2615-109X

\section{ABSTRACT}

One of the Long-Term Contraception Methods (MKJP) is implants. Implant contraception is a contraceptive method that is inserted in the subdermal part, which only contains progestins with a long service life, dose, low, and reversible for women. This study aims to determine the relationship of knowledge and attitudes of EFA with Implant contraception in Samalanga sub-district, Bireuen Regency.

This research is an analytic research with cross sectional approach. Sampling in this study using 43 accidental sampling techniques amounted to Samalanga Health Center, Bireuen District. This research was conducted on September 13-17 2020. Data collection through questionnaires. The univariate data analysis technique uses frequency distribution and bivariate analysis uses the chi-square test.

Chi-square statistical test results of EFA attitudes with implant contraception obtained the value of $p$ value (0.043) <of $\alpha(0.05)$, then the hypothesis is accepted (HO is rejected and Ha is accepted). It can be concluded that there is a significant relationship between EFA attitudes and implant contraception.

It is expected that respondents will be more active in seeking information and attending various counseling, especially regarding Implant Contraception. This can be obtained by increasing reading and attending the seminar.

\section{Keywords: Knowledge, Attitude, Implant Contraception}

\section{PENDAHULUAN}

Mencegah terjadi laju pertumbuhan penduduk yang terus meningkat, pemerintah terus berupaya untuk menekan laju pertumbuhan dengan program keluarga berencana (KB). Sasaran program KB yaitu terkendalinya pertumbuhan penduduk dan meningkatnya keluarga kecil yang berkualitas, untuk mencapai sasaran tersebut yaitu disusun beberapa arahan kebijakan. Salah satu upaya pemerintah meningkatkan pemakaian kontrasepsi yang lebih efektif serta efisien untuk waktu jangka panjang (Lestari, 2015).

Program Keluarga Berencana merupakan salah satu program prioritas dalam Sustainable Development Goals (SDGs), dimana program KB termuat dalam tujuan ketiga (Menjamin Kesehatan yang baik) dan tujuan kelima (menjamin kesetaraan gender serta memberdayakan seluruh wanita) melalui akses terhadap kesehatan reproduksi dan Badan Kependudukan Keluarga Berencana Nasional sebagai motor penggerak dalam melaksanakan Program Keluarga Berencana tersebut (Marbun, 2019).

Metode kontrasepsi jangka panjang (MKJP) merupakan jenis kontrasepsi yang sangat efektif untuk menghindari kelahiran, mengatur interval kelahiran dan tidak mempengaruhi hubungan seksual yang dapat bertahan selama 3 tahun sampai seumur hidup (Nasution, 2018). 
Journal of Healthcare Technology and Medicine Vol. 6 No. 2 Oktober 2020

Universitas Ubudiyah Indonesia

e-ISSN : 2615-109X

Salah satu kontrasepsi jangka panjang (MKJP) adalah implant. Implant adalah salah satu jenis kontrasepsi yang berupa susuk yang terbuat dari sejenis karet silastik yang berisi hormon, dipasang pada lengan atas. Implant dapat digunakan untuk jangka panjang 5 tahun dan bersifat seversible. Keuntungan dari kontrasepsi yang efektifitasnya tinggi, angka kegagalan implant, 1 per 100 wanita pertahun dalam 5 tahun pertama, kegagalan pengguna rendah, sekali terpasang tidak perlu ada yang diingat. Implant berisi levonorgestrel yang merupakan hormon progesteron (Rahayu, 2015).

Pasangan Usia Subur (PUS) adalah pasangan suami-istri yang istrinya berumur antara 15-49 tahun, dan secara operasional pasangan suami-istri yang istri berumur kurang dari 15 tahun dan telah menikah atau istri berumur lebih dari 49 tahun tapi belum menopause. Tingkat kesertaan untuk mengikuti KB diukur dari angka PUS yang menjadi peserta keluarga berencana (KB) (Ismun, 2019).

Pengetahuan mengenai KB sangat penting untuk dimiliki oleh akseptor dalam memilih alat kontrasepsi yang akan dipergunakan karena pengetahuan merupakan domain yang sangat penting dalam membentuk sikap seseorang dalam melakukan suatu tindakan (Andriani, 2018).

Sedikitnya hasil dari Perkiraan Permintaan Masyarakat (PPM) tentang metode kontrasepsi implant membuat ibu tidak berminat memilih kontrasepsi implant karena sikap yang negatif dari masyarakat bahwa implant dapat hilang atau berpindah (Wayanti, 2018).

Berdasarkan data BKKBN (2016), persentase peserta KB di Indonesia pada tahun 2016 sebesar 33,72\%. Angka ini lebih rendah dibandingkan capaian tahun 2015 sebesar $38,75 \%$. Tiga provinsi yang memiliki persentase tertinggi yaitu Aceh (23,3\%), Kalimantan Barat (17,8\%), dan Sumatera Selatan (16,2\%).

Berdasarkan data dari Dinkes Bireuen dari bulan januari-desember 2018 menunjukkan bahwa jumlah PUS di kabupaten Bireuen berjumlah 78493 orang, jumlah keseluruhan akseptor KB Implant di 19 kecamatan kabupaten bireuen sebanyak 943 orang (Dinkes Bireuen, 2019).

Data dari puskesmas samalanga dari bulan januari sampai bulan desember tahun 2018, jumlah keseluruhan PUS di kecamatan samalanga yaitu 5489 orang, peserta aseptor KB Implant berjumlah 42 orang.

Berdasarkan hasil survey awal yang telah dilakukan peneliti di puskesmas Samalanga didapatkan jumlah PUS 5489 orang. Hasil wawancara kepada 10 PUS di puskesmas Samalanga 7 diantaranya tidak mengetahui tentang KB Implant dan ibu belum mengetahui 
Journal of Healthcare Technology and Medicine Vol. 6 No. 2 Oktober 2020

Universitas Ubudiyah Indonesia

e-ISSN : 2615-109X

keuntungan dan kerugian yang ditimbulkan dari KB Implant sedangkan 3 di antaranya sudah mengetahui keuntungan dan kerugian dari KB Implant.

Oleh karena itu peneliti tertarik untuk meneliti tentang "Hubungan Pengetahuan dan Sikap PUS dengan Kontrasepsi Implant Di puskesmas Samalanga, Kabupaten Bireuen Tahun 2020".

Berdasarkan data BKKBN (2016), persentase peserta KB di Indonesia pada tahun 2016 sebesar 33,72\%. Angka ini lebih rendah dibandingkan capaian tahun 2015 sebesar $38,75 \%$. Tiga provinsi yang memiliki persentase tertinggi yaitu Aceh (23,3\%), Kalimantan Barat (17,8\%), dan Sumatera Selatan (16,2\%).

Berdasarkan data dari Dinkes Bireuen dari bulan januari-desember 2018 menunjukkan bahwa jumlah PUS di kabupaten Bireuen berjumlah 78493 orang, jumlah keseluruhan akseptor KB Implant di 19 kecamatan kabupaten bireuen sebanyak 943 orang (Dinkes Bireuen, 2018).

Data dari puskesmas samalanga dari bulan januari sampai bulan desember tahun 2019, jumlah keseluruhan PUS di kecamatan samalanga yaitu 5489 orang, peserta aseptor KB Implant berjumlah 42 orang.

Berdasarkan hasil survey awal yang telah dilakukan peneliti di puskesmas Samalanga didapatkan jumlah PUS 5489 orang. Hasil wawancara kepada 10 PUS di puskesmas Samalanga 7 diantaranya tidak mengetahui tentang KB Implant dan ibu belum mengetahui keuntungan dan kerugian yang ditimbulkan dari KB Implant sedangkan 3 di antaranya sudah mengetahui keuntungan dan kerugian dari KB Implant.

Berdasarkan data diatas, maka peneliti tertarik untuk meneliti tentang "Hubungan Pengetahuan dan Sikap PUS dengan Kontrasepsi Implant Di puskesmas Samalanga, Kabupaten Bireuen Tahun 2020.

Tujuan penelitian ini untuk mengetahui hubungan Pengetahuan dan Sikap PUS dengan Kontrasepsi Implant Di puskesmas Samalanga, Kabupaten Bireuen Tahun 2020.

Penelitian ini diharapkan dapat meningkatkan pengetahuan dan bahan informasi tentang KB Implant.

\section{METODE PENELITIAN}

Desain penelitian yang digunakan adalah penelitian analitik dengan pendekatan cross sectional, yaitu penelitian yang dilakukan dengan tujuan utama untuk membuat gambaran tentang suatu keadaan secara objektif, dimana data yang menyangkut data bebas (resiko) dan 
Journal of Healthcare Technology and Medicine Vol. 6 No. 2 Oktober 2020

Universitas Ubudiyah Indonesia

e-ISSN : 2615-109X

variabel terikat (akibat), untuk melihat hubungan Pengetahuan dan Sikap PUS dengan Kontrasepsi Implant Di puskesmas Samalanga, Kabupaten Bireuen Tahun 2019.

Penelitian ini telah dilakukan di Puskesmas Samalanga, Kabupaten Bireuen. Penelitian ini telah dilaksanakan pada tanggal September 13-17 Mei 2020.

Populasi dalam penelitian ini adalah seluruh PUS yang datang ke Puskesmas Samalanga, Kabupaten Bireuen tahun 2019 sebanyak 43 orang.

Pengambilan sampel diambil secara Accidental sampling atau secara kebetulan yang berjumlah 43 orang.

Jenis data yang digunakan dalam penelitian ini adalah data primer dan data sekunder. Metode pengelohan data collecting, checking, coding, entering dan processing. Analisis data yang digunakan adalah analisis univariat dan analisis bivariat dengan uji chi-square.

\section{HASIL}

Analisis Bivariat : Tabel 1 dapat dilihat tabulasi antara Pengetahuan PUS dengan Kontrasepsi Implant Di Puskesmas Samalanga Kabupaten Bireuen didapatkan hasil bahwa dari 43 responden mayoritas PUS yang berpengetahuan kurang yang tidak memakai kontrasepsi implant yaitu sebanyak 23 responden $(53,5 \%)$.

Dari hasil uji statistik chi-square menunjukkan hubungan antara pengetahuan PUS dengan kontrasepsi Implant didapatkan nilai p $(0,036)<\alpha(0,05)$ maka Ha diterima (Ha diterima dan Ho ditolak) dan dapat disimpulkan bahwa ada hubungan yang bermakna antara pengetahuan PUS dengan Kontrasepsi Implant di Puskesmas Samalanga Kabupaten Bireuen .

Tabel 2 dapat dilihat dari tabulasi antara silang Sikap PUS Dengan Kontrasepsi Implant Di Puskesmas Samalanga Kabupaten Bireuen didapatkan hasil bahwa dari 43 responden mayoritas PUS yang bersikap negatif serta tidak memakai kontrasepsi implant yaitu sebanyak 27 responden $(62,8 \%)$, dan minoritasnya hanya 1 responden $(2,3)$ yang bersikap negatif serta memakai kontrasepsi implant.

Dari hasil uji statistik chi-square menunjukkan hubungan antara sikap PUS dengan Kontrasepsi Implant didapatkan nilai $\mathrm{p}(0,043)<\alpha(0,05)$ maka Ha diterima (Ha diterima dan Ho ditolak) dan dapat disimpulkan bahwa ada hubungan yang bermakna antara sikap PUS dengan Kontrasepsi Implant di Puskesmas Samalanga Kabupaten Bireuen. 
Journal of Healthcare Technology and Medicine Vol. 6 No. 2 Oktober 2020

Universitas Ubudiyah Indonesia

e-ISSN : 2615-109X

Tabel 1 Uji silang antara Pengetahuan PUS dengan Kontrasepsi Implant Di Puskesmas Samalanga Kabupaten Bireuen Tahun 2020

\begin{tabular}{ccccccccc}
\hline & \multicolumn{9}{c}{ Kontrasepsi Implant } & & & & \\
\cline { 2 - 5 } Pengetahuan & Memakai & \multicolumn{2}{c}{ Tidak Memakai } & & $\%$ & $p$ & A \\
\cline { 2 - 5 } & Jml & $\%$ & Jml & $\%$ & & & & \\
\hline Baik & 2 & 4,7 & 5 & 11,6 & 7 & 16,3 & & \\
Cukup & 3 & 7,0 & 10 & 23,3 & 13 & 30,2 & 0,036 & 0,05 \\
Kurang & 0 & 0 & 23 & 53,5 & 23 & 53,5 & & \\
\hline Jumlah & 5 & 11,6 & 38 & 88,4 & 43 & 100 & & \\
\hline
\end{tabular}

Tabel 2 Uji silang Sikap PUS Dengan Kontrasepsi Implant Di Puskesmas Samalanga Kabupaten Bireuen Tahun 2020

\begin{tabular}{ccccccccc}
\hline & \multicolumn{9}{c}{ Kontrasepsi Implant } & & & & \\
\cline { 2 - 5 } Sikap & \multicolumn{2}{c}{ Memakai } & \multicolumn{2}{c}{ Tidak Memakai } & & $\%$ & $P$ & A \\
\cline { 2 - 5 } & Jml & $\%$ & Jml & $\%$ & & & & \\
\hline Positif & 4 & 9,3 & 11 & 25,6 & 15 & 34,9 & & \\
Negatif & 1 & 2,3 & 27 & 62,8 & 28 & 65,1 & & 0,05 \\
\hline Jumlah & 5 & 11,6 & 38 & 88,4 & 43 & 100 & & \\
\hline
\end{tabular}

\section{PEMBAHASAN}

Hubungan Pengetahuan PUS Dengan Kontrasepsi Implant: Dari hasil penelitian yang telah dilakukan pada tanggal 13-17 September 2020 tentang pengetahuan dan sikap PUS dengan Kontrasepsi Implant di Puskesmas Samalanga Kabupaten Bireuen, maka ada beberapa hasil yang ditemukan antara lain, pengetahuan PUS yang ada pada kategori baik yaitu sebanyak 7 responden (16,3\%), kategori cukup 13 responden (30,2\%), dan pada kategori kurang 23 responden $(53,5 \%)$. Maka jelas dapat dilihat bahwa pengetahuan PUS mayoritas berada pada kategori kurang, sehingga perlu ditingkatkan lagi pengetahuan PUS agar lebih memahami Kontrasepsi Implant.

Berdasarkan tabel silang (crosstab) antara pengetahuan PUS dengan kontrasepsi Implant, didapatkan hasil bahwa dari 43 responden mayoritas PUS yang berpengetahuan kurang yang tidak memakai kontrasepsi implant yaitu sebanyak 23 responden $(53,5 \%)$. 
Journal of Healthcare Technology and Medicine Vol. 6 No. 2 Oktober 2020

Universitas Ubudiyah Indonesia

e-ISSN : 2615-109X

Dari hasil uji statistik chi-square antara pengetahuan PUS dengan kontrasepsi Implant didapatkan nilai p $(0,036)<\alpha(0,05)$ maka Ha diterima (Ha diterima dan Ho ditolak) dan dapat disimpulkan bahwa ada hubungan yang bermakna antara pengetahuan PUS dengan Kontrasepsi Implant.

Hal ini menunjukkan bahwa pengetahuan PUS belum cukup baik dalam hal pemakaian kontrasepsi Implant. Pengetahuan PUS yang belum baik dapat juga dipengaruhi oleh tingkat pendidikan, pekerjaan dan umur ibu hamil. Hal ini sesuai dengan pendapat Notoatmodjo (2012) yang menyatakan bahwa pengetahuan dipengaruhi oleh faktor internal yaitu mencakup: pendidikan, pekerjaan, umur dan faktor eksternal mencakup lingkungan, dan sosial budaya.

Pengetahuan adalah hasil "tahu", dan ini terjadi setelah orang melakukan penginderaan terhadap satu objek tertentu. Penginderaan terjadi melalui panca indera manusia, yakni indera penglihatan, pendengaran, penciuman, perasa, dan peraba. Sebagian besar pengetahuan manusia diperoleh melalui mata dan telinga (Notoatmodjo, 2012). Oleh karena itu, semakin banyak hal positif yang didengar dan dilihat oleh seseorang maka semakin besar pula tindakan positif yang dilakukan orang tersebut.

Hasil penelitian yang dilakukan oleh Siregar (2018) tentang "Gambaran pengetahuan WUS dengan Kontrasepsi Implant" Hasil penelitian menunjukkan bahwa mayoritas WUS memiliki pengetahuan kurang tentang KB implant sebanyak 22 orang (44\%). Sedangkan WUS yang berpengetahuan cukup sebanyak 18 orang (36\%), dan berpengetahuan baik sebanyak 10 orang $(20,0 \%)$. Hasil yang diperoleh peneliti sesuai dengan penelitian Windartik. dkk yang memperoleh hasil bahwa sebagian besar responden $(60,5 \%)$ berpengetahuan kurang dan hampir seluruh responden $(89,5 \%)$ dan tidak menggunakan implant.

Hasil penelitian jurnal ilmiah kebidanan yang dilakukan oleh Tui Meihartati (2017) tentang "Faktor-Faktor Yang Berhubungan Dengan Pemilihan Alat Kontrasepsi Implant Di Wilayah Kerja Puskesmas Darul Azhar Kabupaten Tanah Bumbu", hasil penelitian menunjukkan Pemilihan alat kontrasepsi implant di wilayah kerja Puskesmas Darul Azhar Kabupaten Tanah Bumbu tahun 2017, pada kasus responden yang mempunyai sikap mendukung sebanyak 90,9\%, sedangkan 9,1\% meskipun tidak mendukung tetapi tetap menggunakan kontrasepsi implant. Sedangkan pada kelompok kontrol 63,6\% tetap mendukung implant, walaupun mendukung tetap menggunakan alat kontrasepsi yang lain.

Menurut asumsi peneliti, mayoritas PUS berpengetahuan kurang dikarenakan para PUS kurang mengetahui keuntungan dan kerugian yang ditimbulkan dari KB Implant. Hal ini 
Journal of Healthcare Technology and Medicine Vol. 6 No. 2 Oktober 2020

Universitas Ubudiyah Indonesia

e-ISSN : 2615-109X

disebabkan PUS belum sepenuhnya mengerti dan mendapatkan informasi tentang Kontrasepsi Implant. Oleh karena itu, dari pihak puskesmas perlu memberikan penyuluhan tentang Kontrasepsi Implant kepada PUS yang ada di Kecamatan Samalanga serta memberikan motivasi kepada PUS agar memiliki keinginan untuk memasang Kontrasepsi Implant.

Hubungan Sikap PUS Dengan Kontrasepsi Implant: Dari hasil penelitian yang telah dilakukan pada tanggal 13-17 Mei 2019, tentang pengetahuan dan sikap PUS dengan Kontrasepsi Implant di Puskesmas Samalanga Kabupaten Bireuen, maka ada beberapa hasil yang ditemukan antara lain, sikap PUS yang positif yaitu sebanyak 15 responden $(34,9 \%)$ sikap PUS yang negatif yaitu sebanyak 28 responden $(65,1 \%)$.

Berdasarkan tabel silang antara sikap PUS dengan Kontrasepsi Implant, PUS yang memiliki sikap positif namun tidak memakai kontrasepsi implant sebanyak 11 responden $(25,6 \%)$, selebihnya hanya 4 responden $(9,3 \%)$ yang memakai Kontrasepsi Implant, dan 27 responden $(62,8 \%)$ yang memiliki sikap negatif yang tidak memakai Kontrasepsi Implant, selebihnya hanya 1 PUS (2,3\%) yang memakai Kontrasepsi Implant.

Dari hasil uji statistik chi-square antara Sikap PUS dengan kontrasepsi Implant didapatkan nilai $\mathrm{p}(0,043)<\alpha(0,05)$ maka Ha diterima dan Ho ditolak dan dapat disimpulkan bahwa ada hubungan yang bermakna antara sikap PUS dengan Kontrasepsi Implant,

Penelitian terdahulu yang dilakukan oleh Sari (2016) dari Sekolah Tinggi Ilmu Kesehatan Patria Husada Blitar yang melakukan penelitian tentang "Hubungan Pengetahuan Dengan Sikap Ibu Dalam Pemilihan Metode Kontrasepsi Jangka Panjang Pada Wus Di Polindes Gogodeso Kecamatan Kanigoro Kabupaten Blitar", hasil penelitian menunjukkan Berdasarkan analisis penelitian dapat diketahui bahwa hasil uji spearman's rank correlation nilai p value 0,017 (lebih kecil dari 0,05) sehingga dapat disimpulkan bahwa ada hubungan antara pengetahuan dengan sikap responden dalam pemilihan metode kontrasepsi jangka panjang pada WUS di Polindes Gogodeso.

Sikap merupakan reaksi suatu respon seseorang yang masih tertutup suatu stimulasi atau objek. Sikap secara nyata menunjukkan konotasi adanya kesesuaian reaksi terhadap stimulasi tertutup. Newcom merupakan salah seorang ahli psikolog sosial menyatakan bahwa sikap itu merupakan kesiapan atau kesediaan untuk bertindak, dan bukan merupakan pelaksanaan motif tertentu. Sikap belum merupakan suatu tindakan atau aktivitas, akan tetapi merupakan "prediposisi” tindakan atau prilaku. Sikap itu masih merupakan reaksi tertutup, bukan merupakan reaksi terbuka tingkah laku terbuka lebih dapat dijelaskan lagi bahwa sikap merupakan reaksi 
Journal of Healthcare Technology and Medicine Vol. 6 No. 2 Oktober 2020

Universitas Ubudiyah Indonesia

e-ISSN : 2615-109X

terhadap objek dilingkungan tertentu sebagai suatu penghayatan terhadap objek (Notoatmodjo, 2012).

Menurut asumsi peneliti seseorang yang memiliki pendidikan yang tinggi akan lebih memahami tentang kontrasepsi implant serta akan membentuk sikap positif terhadap penerimaanya. Dengan kata lain sikap positif akan lebih banyak ditemukan pada responden yang memiliki tingkat pendidikan yang tinggi dibandingan dengan yang berpendidikan rendah, juga dapat didukung dengan adanya promosi kesehatan yang dilakukan oleh petugas kesehatan yang memiliki pendidikan yang tinggi serta wawasan luas tentang kontrasepsi implant sehingga membantu individu dalam membentuk sikap positif terhadap hal-hal yang bermanfaat baginya.

\section{KESIMPULAN}

Kesimpulan peneliti ini ada ada hubungan yang bermakna antara pengetahuan PUS dengan Kontrasepsi Implant di Puskesmas Samalanga Kabupaten Bireuen tahun 2020 serta ada hubungan yang bermakna antara sikap PUS dengan Kontrasepsi Implant di Puskesmas Samalanga Kabupaten Bireuen tahun 2019.

\section{SARAN}

Disarankan kepada responden untuk lebih aktif mencari informasi dan mengikuti berbagai penyuluhan khususnya tentang kontrasepsi implant. Hal ini dapat diperoleh dengan mengunjungi tempat pelayanan kesehatan dan diharapkan dapat dijadikan bahan informasi bagi puskesmas untuk lebih aktif lagi dalam mensosialisasikan pentingnya kontrasepsi implant bagi PUS dan mampu memotivasi PUS untuk memasang kontrasepsi implant.

\section{DAFTAR PUSTAKA}

Andriani, Y. (2018). Manfaat Penyuluhan Tentang Kb Terhadap Peningkatan Pengetahuan Pada Pasangan Usia Subur (Pus) Tentang Pemasangan Kb. Diambil dari : https://jurnal.stikesperintis.ac.id/index.php/PSKP/article/view/84. Diakses Oleh : Bismi Ulia 15 april 2019, 11.04 wib.

Data Dinkes Bireuen (2018) ( data lapangan yang diambil tanggal 09 April 2019)

Depkes RI. (2018) Diambil Dari http://www.depkes.go.id/resources/download/pusdatin/profil-kesehatan- 
Journal of Healthcare Technology and Medicine Vol. 6 No. 2 Oktober 2020

Universitas Ubudiyah Indonesia

e-ISSN : 2615-109X

indonesia/Profil-Kesehatan-Indonesia-2018.pdf. Diakses Oleh : Bismi Ulia 15 april 2019, 11.04 wib.

Everett, S (2012). Kontrasepsi Dan Kesehatan Seksual Reproduktif. Jakarta : EGC

Hasmiatin, (2016). Hubungan Pengetahuan, Dukungan Suami Dan Budaya Dengan Penggunaan Alat Kontrasepsi Implant Pada Pasangan Usia Subur Di Wilayah Kerja Puskesmas Abeli Kecamatan Abeli Kota Kendari. Diambil dari : http://sitedi.uho.ac.id/uploads_sitedi/F1D311072_sitedi_skripsi.pdf. Diakses oleh: Bismi Ulia 15 april 2019, 11.04 wib.

Iman, M (2016). Panduan Penyusunan Karya Tulis Ilmiah Bidang Kesehatan. Bandung : Citapustaka Media Perintis

Lestari, L. (2015). Gambaran Akseptor Implant Di Puskesmas Gamping Ii Sleman. Diambil dari : http://repository.unjaya.ac.id/485/. Diakses Oleh: Bismi Ulia 21 april 2019, 10.00 wib.

Marbun, A.R (2019). Faktor-Faktor Yang Mempengaruhi Partisipasi Pria Dalam Vasektomi Di Kecamatan Sidikalang. Diambil dari : http://ojs.stikesimelda.ac.id/index.php/jilki/article/view/339. Diakses Oleh: Bismi Ulia 16 april 2019, 10.21 wib.

Meihartati, T. (2016). Faktor-Faktor Yang Berhubungan Dengan Pemilihan Alat Kontrasepsi Implant Di Wilayah Kerja Puskesmas Darul Azhar Kabupaten Tanah Bumbu. Diambil dari : http://idr.uin-antasari.ac.id/id/eprint/6825. Diakses Oleh: Bismi Ulia 16 april 2019, 10.30 wib.

Mellani, N. (2012). Pelayanan Keluarga Berencana. Yogyakarta : Citramaya

Nasution, P (2018). Analisis Faktor Untuk Mengetahui Hambatan Dalam Penggunaan Kontrasepsi Implan Di Desa Suka Maju Kecamatan Sunggal Kabupaten Deli Serdang. Diambil Dari : http://ejournal.helvetia.ac.id/index.php/jbk. Diakses Oleh: Bismi Ulia 20 april 2019, 11.00 wib.

Notoatmodjo, S. (2012). Teori Pengetahuan dan Pengembangannya. Jakarta: PT. Rineka Cipta

Rusmini, (2017). Pelayanan KB Dan Kesehatan Reproduksi. Jakarta : CV. Trans Info Media

Sari, W.D.T. (2016). Hubungan Pengetahuan Dengan Sikap Ibu Dalam Pemilihan Metode Kontrasepsi Jangka Panjang Pada Wus Di Polindes Gogodeso Kecamatan Kanigoro Kabupaten Blitar. Diamil dari : http://eprints.ums.ac.id/48268/25/PUBLIKASI\%20ILMIAH.pdf. Diakses Oleh: Bismi Ulia 20 april 2019, 11.30 wib.

Siregar, D.B. (2018) Gambaran Pengetahuan Wus Tentang Kb Implant Di Klinik Ela Azmi. diambil dari : http://jurnal.unprimdn.ac.id/index.php?journal=Jumkep. Diakses oleh: Bismi Ulia 15 april 2019, 08.04 wib.

Trisnawati, A. (2017). Gambaran Tingkat Pengetahuan Wanita Usia Subur (Wus) Akseptor $\mathrm{Kb}$ Yang Berkunjung Tentang Kontrasepsi Implan Di Puskesmas Gedong tengen Kota Yogyakarta.

Diambil dari

http://repository.unjaya.ac.id/2441/2/AGUS\%20TRISNAWATI\%20\%281113167\%29 nonfull.pdf. Diakses Oleh: Bismi Ulia 24 april 2019, 10.00 wib.

Wkerkwa, B. (2017). Faktor-Faktor Yang Berhubungan Dengan Penggunaan Metode Kontrasepsi Implant Di Wilayah Kerja Puskesmas Teladan Kecamatan Medan Kota. Diambil Dari : 
Journal of Healthcare Technology and Medicine Vol. 6 No. 2 Oktober 2020

Universitas Ubudiyah Indonesia

e-ISSN : 2615-109X

http://repositori.usu.ac.id/bitstream/handle/123456789/1782/121000540.pdf?sequence $=1 \&$ isAllowed=y. Diakses oleh: Bismi Ulia 26 april 2019, 08.04 wib. 